\title{
Silica-Coated Liposomes for Insulin Delivery
}

\author{
Neelam Dwivedi, ${ }^{1,2}$ M. A. Arunagirinathan, ${ }^{1}$ Somesh Sharma, ${ }^{2}$ and Jayesh Bellare ${ }^{1}$ \\ ${ }^{1}$ Department of Chemical Engineering, Indian Institute of Technology Bombay, Mumbai 400076, India \\ ${ }^{2}$ Piramal Life Sciences Limited, Research and Development Division, Mumbai 400063, India
}

Correspondence should be addressed to Jayesh Bellare, jb@iitb.ac.in

Received 4 November 2009; Revised 14 March 2010; Accepted 22 March 2010

Academic Editor: Maryam Tabrizian

Copyright ( 2010 Neelam Dwivedi et al. This is an open access article distributed under the Creative Commons Attribution License, which permits unrestricted use, distribution, and reproduction in any medium, provided the original work is properly cited.

Liposomes coated with silica were explored as protein delivery vehicles for their enhanced stability and improved encapsulation efficiency. Insulin was encapsulated within the fluidic phosphatidylcholine lipid vesicles by thin film hydration at $\mathrm{pH} 2.5$, and layer of silica was formed above lipid bilayer by acid catalysis. The presence of silica coating and encapsulated insulin was identified using confocal and electron microscopy. The native state of insulin present in the formulation was evident from Confocal MicroRaman spectroscopy. Silica coat enhances the stability of insulin-loaded delivery vehicles. In vivo study shows that these silica coated formulations were biologically active in reducing glucose levels.

\section{Introduction}

Over several decades pharmaceutical drug manufacturers are using different drug carriers like liposomes, microemulsion, polymeric nanoparticles, ceramic nanocomposites, silica, and titania [1]. Recent review by Porter et al. gives overview on lipid-based formulations of lipophilic drugs and their oral bioavailability [2]. Application of micelles, cochleate, sphingosomes, and vesicles for delivering various drugs and immunogens has been explained by Shapira et al. [3]. Silicalipid hybrids have been used for enhanced oral absorption of hydrophobic drugs like celecoxib and indomethacin [46]. Cationic lipid-coated silica nanoparticles were used for protein and vaccine delivery due to their controlled cellular immune response and improved pharmacokinetics $[7,8]$. Silica-lipid hybrids as nonporous nanospheres and thin films has been prepared from dipalmitoylphosphatidylcholine and egg phosphatidylcholine with varying cholesterol content $[4,6,9]$. Encapsulation of insulin, gramicidin, bacteriorhodopsin within phospholipid vesicles by varying cholesterol/lipid ratio and $\mathrm{pH}$ have been reported earlier, however, lipid bilayer stabilized by inert material like silica has not been studied for insulin delivery [10-16].

Silica nanospheres prepared from noncovalently bound organic templates (surfactant, polymers, supramolecular arrays), acoustic cavitation, electrospraying, spray drying, self assembly, freeze thawing, supercritical fluid technology, heterophase polymerization with sol-gel and surface living polymerization process have been reported [17-24]. Solgel derived silica nanospheres were used to encapsulate antibiotics, analgesic, pancreatic islets, dyes and perfumes. It is also used in chromatography, catalysis, waste removal and as fillers in coating $[25,26]$.

It is established that silica coating is chemically inert, biocompatible, hydrophilic and inexpensive. Here, we have prepared liposome having layer of silica to enhance the stability of the formulation. This formulation has improved encapsulation efficiency of macromolecule within the liposome by inhibiting leakage of insulin due to presence of outer silica coat. The present formulation can be used for encapsulation of peptides.

\section{Experimental}

2.1. Materials. Phosphatidylcholine (PC), Bovine insulin, and Tetra ethyl orthosilicate (TEOS) were obtained from Sigma-Aldrich.

2.2. Synthesis of Silica Coated PC Nanosphere. To obtain silica coated PC nanosphere, initially a thin film of phosphatidylcholine (PC) was obtained on the walls of round 
bottomed flask by evaporating $10 \mathrm{ml}$ of chloroform solution containing $100 \mathrm{mg}$ of PC under reduced pressure. The thin film of PC was hydrated by adding $100 \mathrm{ml}$ of water and stirred for 15 minutes. The stirred mixture was further sonicated for 10 minutes to obtain vesicles. To this vesicular dispersion, $5 \mathrm{ml}$ of TEOS was added at a mole ratio $0.9: 17: 4$ (TEOS: $\mathrm{PC}: \mathrm{H}_{2} \mathrm{O}$ ), and $\mathrm{pH}$ of the mixture was decreased to 2.5 by adding $0.05 \mathrm{~N} \mathrm{HCl}$ and then stirred for 2 hours. This reaction mixture was kept for aging at acidic $\mathrm{pH}$ of 2.5 for 24 hours to increase silica network formation leading to PC vesicles coated with silica. This solution was stored at $4^{\circ} \mathrm{C}$ for further studies.

\subsection{Synthesis of Silica Coated PC Nanosphere Encapsulating} Insulin. Whereas to obtain insulin loaded silica coated PC nanosphere, $10 \mathrm{mg}$ of insulin was dissolved in $1 \mathrm{ml}$ of distilled water to which 10 microlitre of $0.05 \mathrm{~N} \mathrm{HCl}$ was added. Similarly for confocal microscopy studies FITC tagged insulin was used. This insulin solution was further diluted with distilled water to obtain total volume of $100 \mathrm{ml}$ and later added to thin film of PC obtained from evaporating $100 \mathrm{mg}$ of PC dissolved in $10 \mathrm{ml}$ of chloroform in round bottom flask for hydration. This solution was stirred for 15 minutes followed by 10 minutes of sonication, and $5 \mathrm{ml}$ of TEOS was added which is then stirred for 2 hours and 24 hours aging. The reaction mixture was centrifuged for 5 minutes, supernatant was discarded, and the bottom settled portion of material was resuspended in $50 \mathrm{ml}$ of distilled water then again centrifuged for 5 minutes. The supernatant was discarded and the paste like mass ( silica coated insulin loaded vesicles) settled at the bottom was stored at $4^{\circ} \mathrm{C}$ for further studies.

\subsection{Characterisation of Silica Coated PC Nanosphere Formulation}

2.4.1. Confocal Microscopy. Fluorophore tagged insulin (FITC-insulin) containing formulations was observed on glass cover slips under Confocal Laser Scanning Microscope (Fluoview FV500, Olympus) using Multi Argon Laser, $488 \mathrm{~nm}$.

2.4.2. TEM. To observe the microstructures of silica coated insulin loaded PC vesicles under TEM (Tecnai-12, FEI), simple drying, room temperature replica and Freeze fracture replica were done. For simple drying, a drop of the sample was allowed to dry on 300 mesh TEM grid having Formvar film stabilized with carbon coating and observed under TEM. Room temperature replica of the samples were prepared by placing a drop of sample on a glass cover slip and allowed to dry at room temperature. After drying, replica was made by coating $2 \mathrm{~nm}$ of $\mathrm{Pt} / \mathrm{C}$ at 45 degree angle followed by $40 \mathrm{~nm}$ carbon coating at 90 degree angle in Balzer BAF060 freeze fracture unit. The cover slip containing the coated sample was submerged in sodium hypochlorite solution for 1 hour to facilitate detachment of replica from the sample. The detached replica was further gently washed with distilled water and lifted over bare carbon TEM grid and allowed to dry. The obtained replica was later observed under TEM.

To obtain freeze-fractured replica of the sample, 5-10 $\mu \mathrm{l}$ of the sample was placed between two copper planchets obtained from Baltec and held by flat tip, rounded end, Dumont tweezer then plunged quickly into liquid nitrogen. The sandwiched copper planchets containing frozen sample was inserted on to the slot of double replica specimen table kept under liquid nitrogen and transferred through cold chain on to the precooled stage maintained at $-150^{\circ} \mathrm{C}$ in Balzer BAF060 freeze fracture unit. The sandwiched copper planchets were made open inside the freeze fracture unit. The fractured frozen sample was coated with $2 \mathrm{~nm}$ of $\mathrm{Pt} / \mathrm{C}$ at 45 -degree angle followed by $40 \mathrm{~nm}$ carbon coating at 90 degree angle. The coated fractured specimen was brought to room temperature and submerged in sodium hypochlorite solution for 1 hour to facilitate detachment of replica from the sample. The detached replica was further gently washed with distilled water and lifted over bare carbon TEM grid and allowed to dry. The obtained replica was later observed under TEM.

2.4.3. HPLC. Insulin content of the samples was analyzed using HPLC-UV at $277 \mathrm{~nm}$ (Waters, Photo diode array detector). Gradient elution was performed using $100 \%$ acetonitrile and $0.1 \%$ TFA $(0.1 \%)$ at a flow rate of $1 \mathrm{ml} /$ minutes and injection volume of $20 \mu \mathrm{l}$. Insulin was detected at a retention time of 5.7 minutes with detection limit of $0.01 \mathrm{mg} / \mathrm{ml}$. To check the total release of insulin, $100 \mu \mathrm{l}$ of $25 \mathrm{mM}$ EDTA and $100 \mu \mathrm{l}$ of $10 \%$ Triton-X 100 was added to the $100 \mu \mathrm{l}$ of formulation.

2.4.4. FTIR. Bovine insulin powder and silica-PC-insulin nanosphere mixed with $\mathrm{KBr}$ and compressed into discs by $20 \mathrm{kN}$ force at room temperature were studied by FTIR (Magna 550, Nicolet Instruments Corporation, USA).

2.4.5. Confocal Micro Raman Spectroscopy. Samples kept on glass cover slips were focused with Olympus optical microscope attached with Confocal Micro Raman spectrometer (Labram HR 800, Horiba Jobin Yvon) using 20X objective and spectra were recorded as an average of 3 scans with a time span of 30 second each using Ar laser, $514.5 \mathrm{~nm}, 20 \mathrm{~mW}, 6$ A.

2.4.6. SGF and SIF Study. A $50 \mathrm{mg}$ formulation containing $0.45 \mathrm{mg}$ of insulin and control ( $1 \mathrm{mg}$ of insulin alone) were added separately to $2 \mathrm{~mL}$ of simulated gastric fluid (SGF) and simulated intestinal fluid (SIF) in triplicate and studied at $37^{\circ} \mathrm{C}$ in shaking mode. A $100 \mu \mathrm{L}$ of the sample was withdrawn at definite interval and reaction was arrested by adding chilled $100 \mu \mathrm{L}$ acetonitrile. The amount of insulin released over a period of 60 minutes in SGF and SIF was determined using HPLC [27].

\subsubsection{Biological Activity of Silica Coated PC Formulation in} Wistar Rats. The biological activity of insulin-encapsulated in silica-PC nanospheres was tested in a rat model (Wistar rats, $200 \pm 25 \mathrm{~g}, n=3$ ) by measuring decrease in blood 


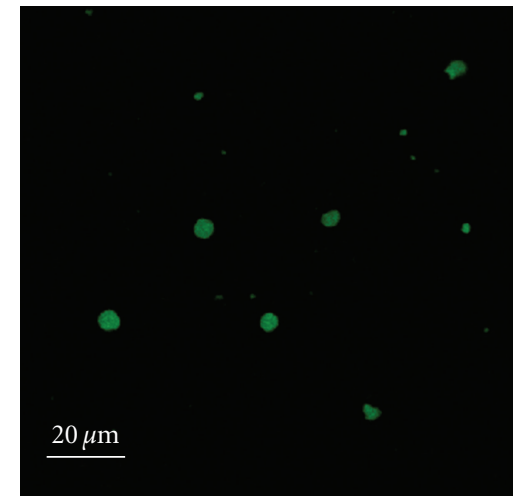

(a)

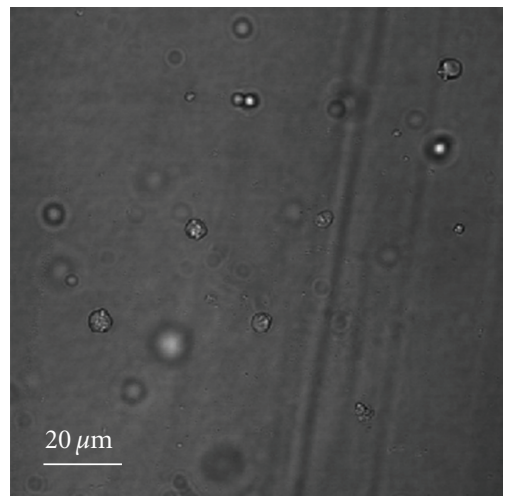

(b)

FIgURE 1: Confocal microscopy of FITC-insulin-encapsulated phosphatidylcholine vesicles. (a) Confocal mode (b) DIC mode. Bar = 20 micron.

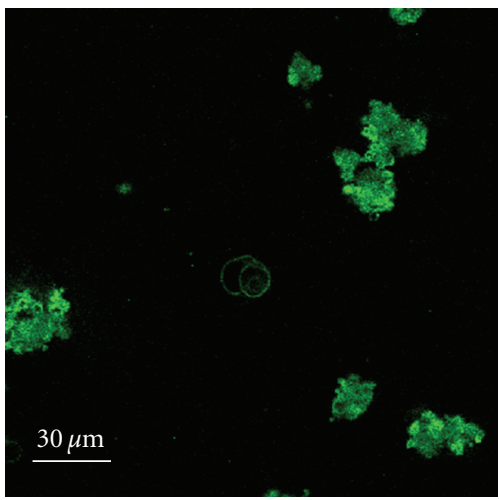

(a)

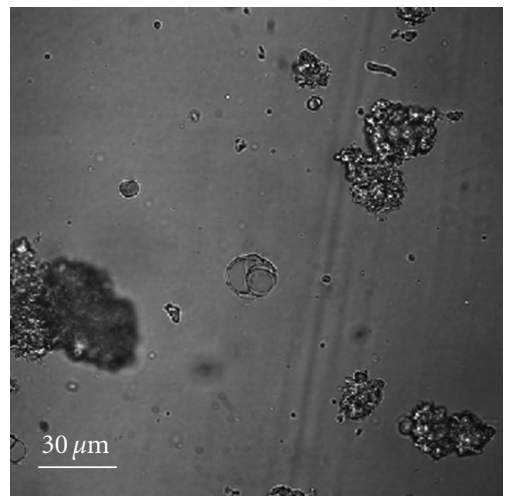

(b)

Figure 2: Silica coated phosphatidylcholine vesicles encapsulated with FITC-insulin. (a) Confocal mode (b) DIC mode. Bar $=30$ micron.

glucose level. Animals fasted overnight (16 hours) were anesthetized with $5 \% \mathrm{v} / \mathrm{v}$ isoflurane obtained from Isorane. Experimental animals considered as standard set received a subcutaneous injection of bovine insulin (4 IU/kg) while control animals were kept as they are without administering insulin or formulation and the test animals were subcutaneously administered with formulation containing silica coated liposomes encapsulated with $28 \mathrm{IU} / \mathrm{kg}$ of insulin. A $0.3 \mathrm{ml}$ of blood samples were withdrawn into eppendorf tubes containing 1.5 microlitre heparin at 0, 30, 60, 120, 240 minutes interval after subcutaneous injection. Blood samples were then centrifuged at 4 degree $\mathrm{C}, 7000 \mathrm{rpm}$ to separate plasma from red blood cells. A 30 microlitre of plasma was mixed with 150 microlitre of saline and vortexed for few seconds and subjected to insitu glucose oxidase method in Hitachi 902, glucose analyzer. The results were expressed as the mean \pm S.E.

\section{Results and Discussion}

Silica coated insulin-encapsulated phosphatidylcholine (PC) vesicle obtained by transcriptive templating mechanism was studied for glucose reduction. Protective coating of soft drug delivery vehicles are of immense importance to deliver the drug in its active state from the deleterious action of gastric enzymes and $\mathrm{pH}$ effect. Hollow silica vesicles obtained at higher temperature by hydrothermal synthesis using zwitterionic, cationic and catanionic surfactant vesicle as template have been reported earlier for various applications [28-30]. Here, silica coated insulin loaded liposomes were prepared at room temperature by acid catalyzed polymerisation of silica precursor. The acid catalysed polymerisation prevents the extensive growth of polymeric silica framework thereby favoring the formation of nanoparticles instead of large micrometer sized-particles. Proteins find more stable environment upon encapsulation in a lipid-silica host, because of polymeric silica frame that grows around phospholipids and protects it from gastric denaturation.

Silica coated insulin loaded PC nanosphere studied were formed by supersaturation of anionic silanol species above the insulin-encapsulated PC nanosphere due to electrostatic interaction. At reaction conditions of $\mathrm{pH} 2$ the cationic nature of PC facilitates polyelectrolytic condensation of anionic silica above it leading to extensive silica coat over insulin-encapsulated PC nanosphere. Initiation of silica 


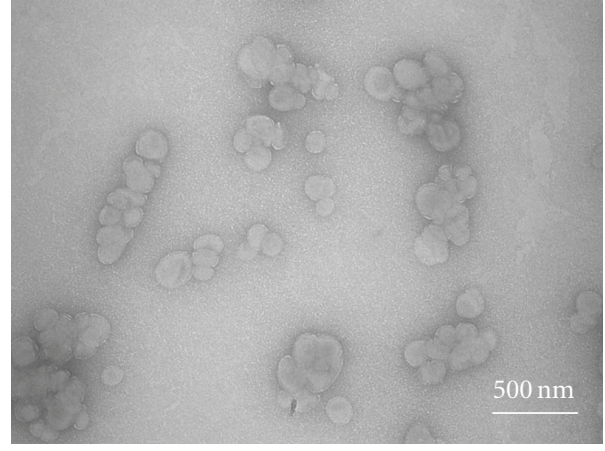

(a)

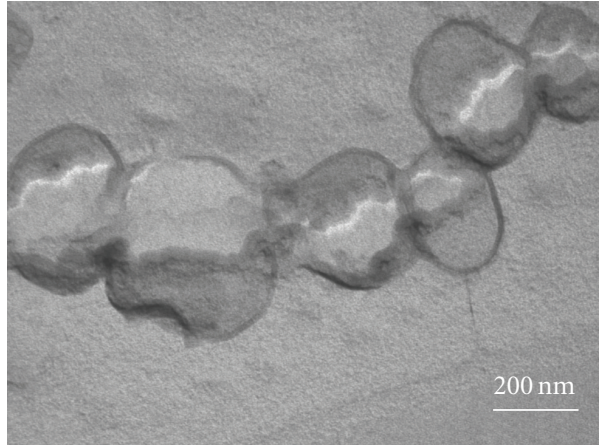

(b)

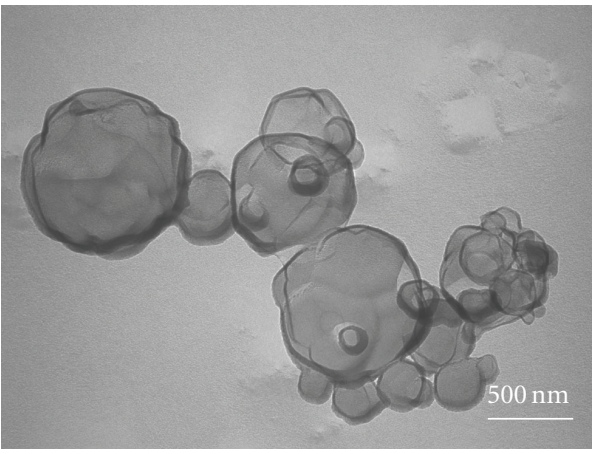

(c)

FIGURE 3: (a) TEM image of silica coated PC nanosphere. (b) Replica TEM image of silica coated PC nanosphere. (c) Freeze-fractured TEM image of silica coated PC nanosphere encapsulated with insulin.

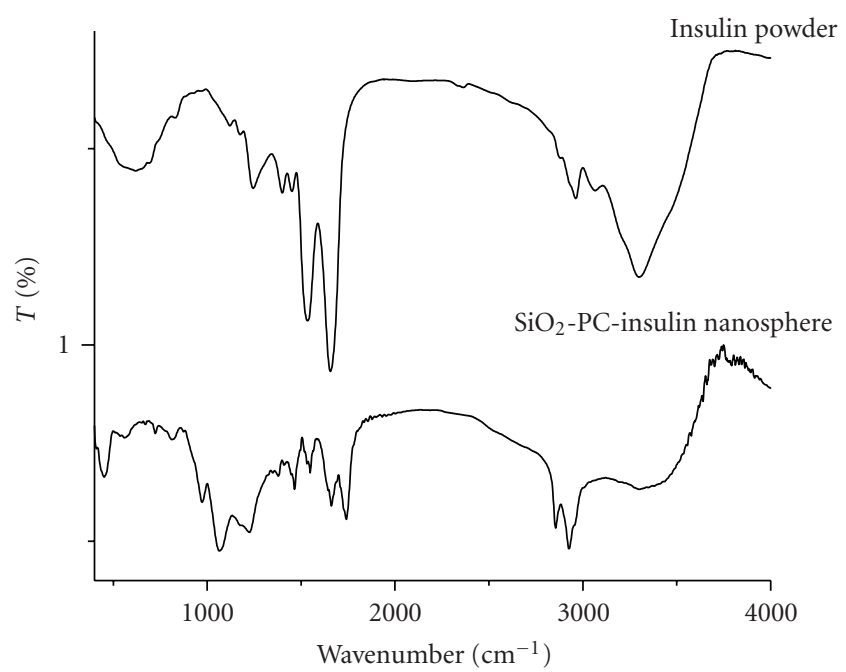

FIGURE 4: FTIR spectra of bovine insulin powder and silica coated $\mathrm{PC}$ nanosphere encapsulated with insulin.

growth above the surface of insulin loaded PC nanosphere occurs through hydrolysis of silica precursor at lower $\mathrm{pH}$ (2.5) and promotes colloidal silica formation by release of alcohol followed by silanol condensation leading to gelation. Presence of silica coating around insulin loaded PC nanosphere prevents it from denaturation due to $\mathrm{pH}$ and enzymes [31-36].

Insulin encapsulation within $\mathrm{PC}$ vesicles and silica coated PC nanosphere was studied by Confocal microscopic investigation using FITC-insulin during encapsulation. Fluorescent nature of the FITC-insulin loaded PC vesicles (Figure 1(a)) and silica coated FITC-insulin loaded PC vesicles (Figure 2(a)) confirmed the presence of FITC-insulin in the formulations. Quasiaggregated state of silica coated FITC-insulin loaded PC vesicles (Figures 2(a) and 2(b)) indicate formation of silica coat and further silica growth by polyelectrolytic condensation of silica on FITC-insulin loaded PC vesicles. Due to polyelectrolytic condensation, the initially deposited silanol on freely dispersed PC vesicles loaded with FITC-insulin acted as bridge for further interaction among themselves leading to aggregation. Encapsulated insulin in the formulations was found to be $80 \%( \pm 6 \%)$ from HPLC analysis. Transmission electron microscopic study of room temperature dried, silica coated PC nanosphere samples revealed fusion of nanosphere (Figure 3(a)). The nanosphere in the range of $200 \mathrm{~nm}$ implies its advantage as drug delivery vehicle. The fusion of silica coated PC nanosphere indicate strong interparticle interaction which could be due to silanol bonding between silica coating present on the nanospheres as well as polyelectrolytic bridging interaction between cationic PC through anionic silica. Similar inference can also be arrived from TEM observation 


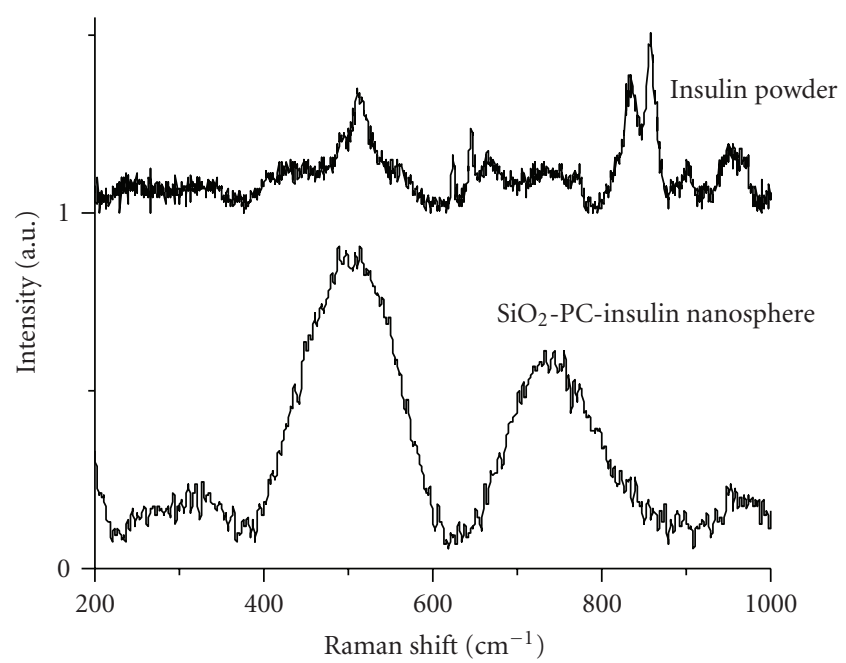

(a)

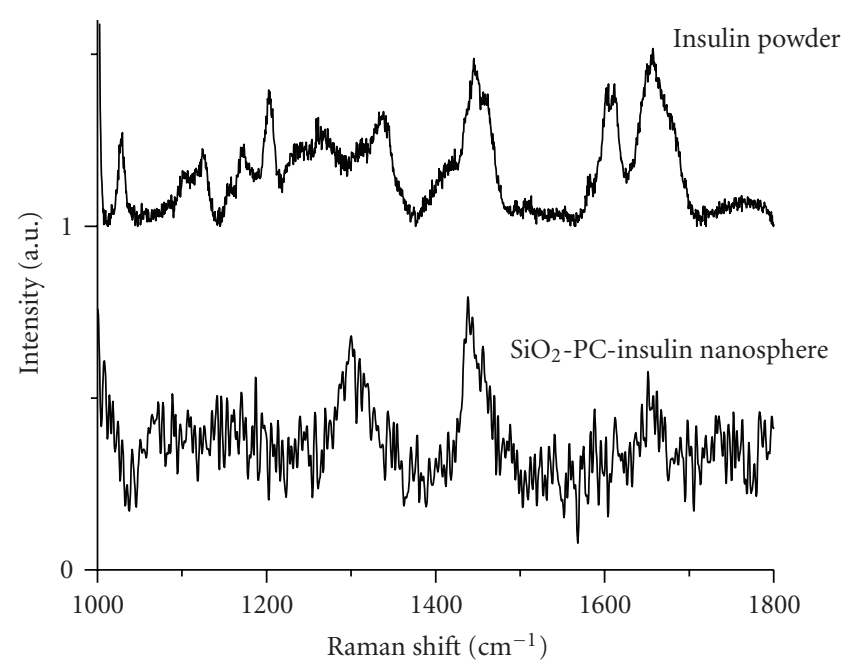

(b)

Figure 5: (a) Confocal micro Raman spectra of bovine insulin powder and silica coated PC nanosphere encapsulated with insulin (200-1000 $\left.\mathrm{cm}^{-1}\right)$. (b) Confocal micro Raman spectra of bovine insulin powder and silica coated PC nanosphere encapsulated with insulin $\left(1000-1800 \mathrm{~cm}^{-1}\right)$.

of room temperature replica of silica coated PC nanosphere (Figure 3(b)). Freeze-fractured TEM observation of silica coated insulin loaded PC nanosphere confirmed the fusion of smaller nanospheres below $200 \mathrm{~nm}$ and existence of nanoparticles less than $500 \mathrm{~nm}$ (Figure 3(c)). FTIR and Confocal Micro Raman spectroscopy studies were carried out to confirm the presence of insulin, silica coating, and biologically active state of insulin in the formulations. Silica coated insulin loaded PC nanosphere formulation having infrared absorption (Figure 4) around $3288 \mathrm{~cm}^{-1}$ (amide A band), $1644 \mathrm{~cm}^{-1}$ (amide I), $1514 \mathrm{~cm}^{-1}$ (amide II) and $1236 \mathrm{~cm}^{-1}$ (amide III), in comparison with standard bovine insulin confirmed the presence of insulin in the formulation. Silica coating present in the formulation was evident from

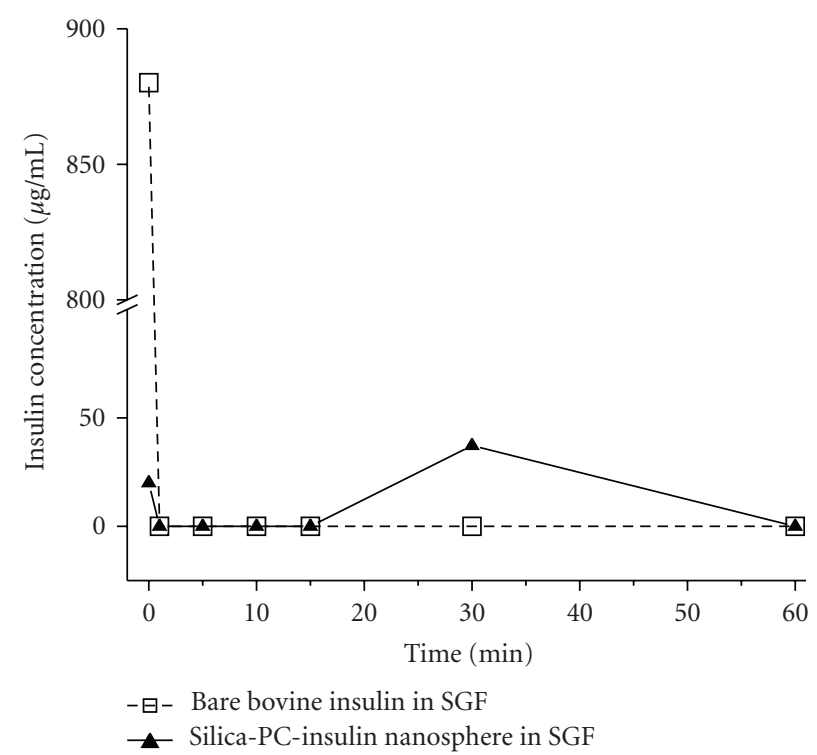

(a)

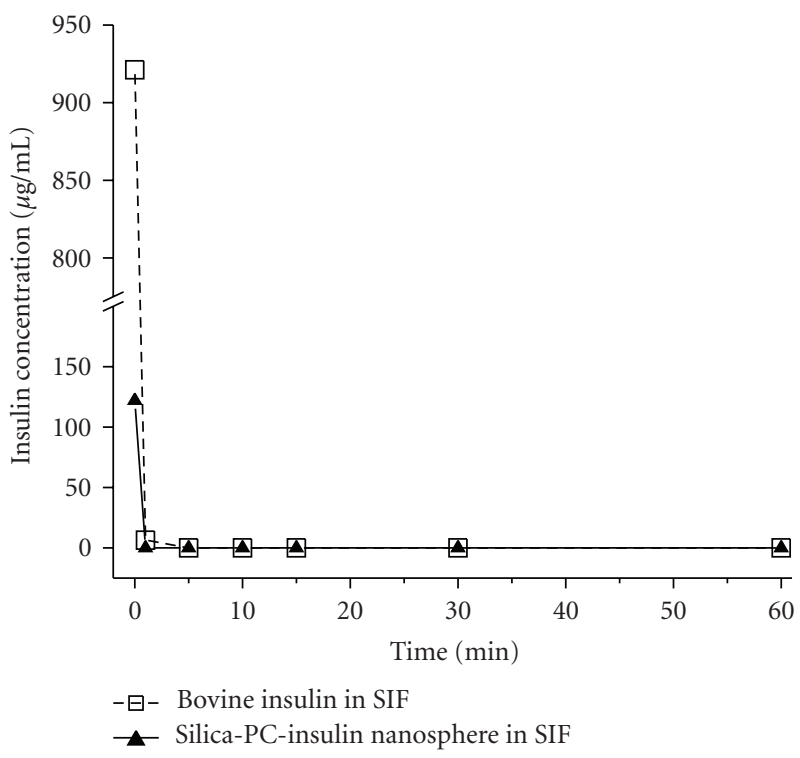

(b)

FIgure 6: (a) Release of insulin from silica coated PC nanosphere formulation in simulated gastric fluid. (b) Release of insulin from silica coated PC nanosphere formulation in simulated intestinal fluid.

Si-O stretching at $1080 \mathrm{~cm}^{-1}, \mathrm{Si}-\mathrm{OH}$ at $950 \mathrm{~cm}^{-1}$, Si-OSi bending at $800 \mathrm{~cm}^{-1}$ and $\mathrm{Si}-\mathrm{O}$ bending at $470 \mathrm{~cm}^{-1}$ [37]. Similarly Si-O tetrahedral vibration at $495 \mathrm{~cm}^{-1}$ as observed in MicroRaman also indicates presence of silica coating. The biologically active state of insulin in silica coated insulin loaded PC nanosphere formulation was confirmed from Raman shifts due to S-S stretching at $505,517 \mathrm{~cm}^{-1}$, whereas C-S stretching at $668 \mathrm{~cm}^{-1}$ was masked by broad peak due to $\mathrm{Si}-\mathrm{O}-\mathrm{Si}$ symmetric stretching $670-800 \mathrm{~cm}^{-1}$ in comparison with standard insulin by Confocal Micro Raman Spectroscopy (Figure 5(a)). Presence of disulphide 


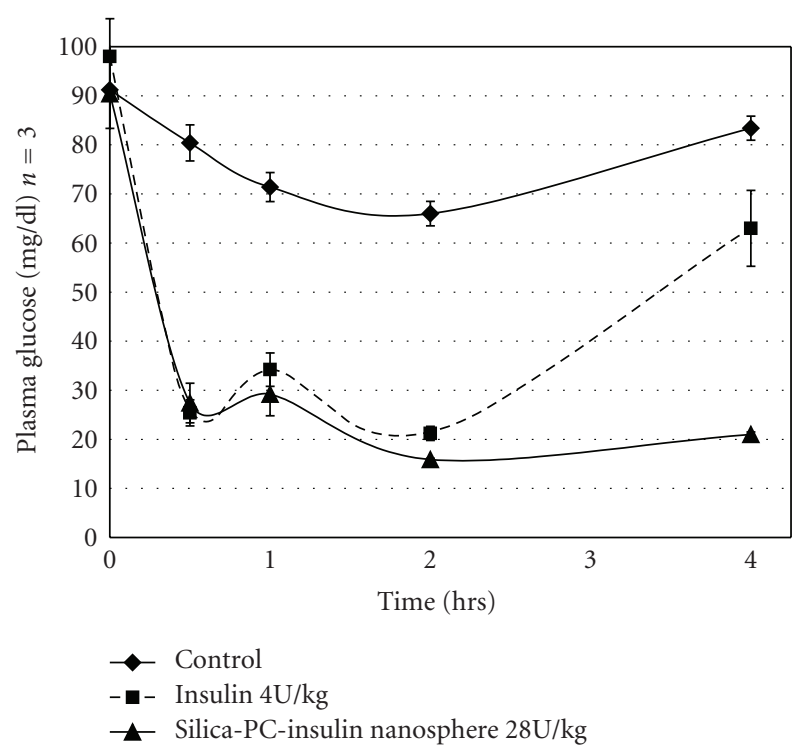

Figure 7: Subcutaneous activity of silica coated PC nanosphere encapsulated with insulin. Insulin released from the Silica-PCInsulin Nanosphere is able to reduce glucose level for longer duration.

stretching and amide stretching (around $1270 \mathrm{~cm}^{-1}$ and $1670 \mathrm{~cm}^{-1}$, Figure 5(b)) confirms the chemical stability of insulin-encapsulated in formulation [38-40].

Room temperature processed silica xerogels are extensively used as carriers for the controlled release of enzymes, proteins and pharmaceutical substances [41]. Silica coating present on lipid prevents it from rapid degradation in the gut lining. Release of insulin from silica coated insulin loaded PC nanosphere can occur through both diffusion and dissolution through pores present in these nanoparticles. Therefore, chemical and structural characteristics of the silica xerogel strongly affect their drug release behavior [42]. The insulin monomer has multiple ionizable groups due to six amino acid residues capable of attaining positive charge and other 10 amino acid residues capable of attaining negative charge [43]. This polyelectrolytic nature of insulin can be attributed for the entrapment of insulin in the formulation.

The stability of formulation towards $\mathrm{pH}$ and enzyme is inferred from small amount of total insulin released $0.057 \mathrm{mg}(12.8 \%)$ in SGF and $0.122 \mathrm{mg}(26.6 \%)$ in SIF (Figures 6(a) and 6(b)). This indicates that silica coating present in the formulation is slowly solubilised at higher $\mathrm{pH}$ in SIF while being protected relatively stronger at lower $\mathrm{pH}$ in gastric fluid and releases the encapsulated insulin when there is a maximum absorption. In vivo studies in Wistar rats indicated that these silica coated insulin-encapsulated PC nanospheres were effective in decreasing glucose level in comparison with standard insulin by parental route with $28 \mathrm{IU} / \mathrm{kg}$ (Figure 7). The variation in blood glucose level with initial reduction and later gradual increase as observed in control group of animals can be attributed to overnight fasting of rats. Glucagon hormone promotes glycogen breakdown or conversion of protein/amino acid or fatty acid to glucose, in order to maintain minimum glucose level for normal function of brain when glucose supplement is not available from glycolysis. Thus glucose level increases after initial drop [44-47]. It is presumed that the porous nature of the silica coated phostphatidylcholine nanosphere formulation would have facilitated in releasing the entrapped insulin thereby reducing the blood glucose level.

\section{Conclusion}

Sol-gel derived silica is biocompatible and biodegradable inorganic carrier material. Its bioresorbability occurs by hydrolysis of siloxane bonds in human body and it is excreted via kidneys [48]. The silica-PC-insulin formulation described here was found to be effective in reducing glucose level. Silica and PC framework is a probable host for biological activity of proteins that is otherwise vulnerable for denaturation. Native state of insulin in this formulation is confirmed by its bioactivity in corroboration with spectroscopy. The present formulation may be used for oral delivery of insulin which could enhance the absorption of nanoparticle in intestine through Peyer's patch.

\section{Acknowledgment}

Part of this work was carried out at Sophisticated Analytical Instrumentation Facilities; IIT Bombay is gratefully acknowledged.

\section{References}

[1] S. P. Victor and T. S. Sampath Kumar, "BCP ceramic microspheres as drug delivery carriers: synthesis, characterisation and doxycycline release," Journal of Materials Science: Materials in Medicine, vol. 19, no. 1, pp. 283-290, 2008.

[2] C. J. H. Porter, C. W. Pouton, J. F. Cuine, and W. N. Charman, "Enhancing intestinal drug solubilisation using lipid-based delivery systems," Advanced Drug Delivery Reviews, vol. 60, no. 6, pp. 673-691, 2008.

[3] I. Shapira, D. R. Budman, T. Bradley, and R. Gralla, "Evolving lipid-based delivery systems in the management of neoplastic disease," Oncology Reviews, vol. 3, no. 2, pp. 113-124, 2009.

[4] A. Tan, S. Simovic, A. K. Davey, T. Rades, and C. A. Prestidge, "Silica-lipid hybrid (SLH) microcapsules: a novel oral delivery system for poorly soluble drugs," Journal of Controlled Release, vol. 134, no. 1, pp. 62-70, 2009.

[5] S. Simovic, P. Heard, H. Hui, et al., "Dry hybrid lipid-silica microcapsules engineered from submicron lipid droplets and nanoparticles as a novel delivery system for poorly soluble drugs," Molecular Pharmaceutics, vol. 6, no. 3, pp. 861-872, 2009.

[6] G. Gupta, G. P. Lopez, and P. Atanassov, "Hybrid materials based on silica/lipid assemblies with incorporation of transmembrane proteins," in Proceedings of the AIChE Annual Meeting, p. 14231, 2005, 05AIChE.

[7] N. Lincopan, M. R. A. Santana, E. Faquim-Mauro, M. H. B. da Costa, and A. M. Carmona-Ribeiro, "Silica-based cationic bilayers as immunoadjuvants," BMC Biotechnology, vol. 9, article 5, 2009. 
[8] J. Liu, A. Stace-Naughton, X. Jiang, and C. J. Brinker, "Porous nanoparticle supported lipid bilayers (protocells) as delivery vehicles," Journal of the American Chemical Society, vol. 131, no. 4, pp. 1354-1355, 2009.

[9] S. Bégu, S. Girod, D. A. Lerner, N. Jardiller, C. Tourné-Péteilh, and J.-M. Devoisselle, "Characterization of a phospholipid bilayer entrapped into non-porous silica nanospheres," Journal of Materials Chemistry, vol. 14, no. 8, pp. 1316-1320, 2004.

[10] Y. Li and A. K. Mitra, "Effects of phospholipid chain length, concentration, charge, and vesicle size on pulmonary insulin absorption," Pharmaceutical Research, vol. 13, no. 1, pp. 7679, 1996.

[11] R. N. Farias, A. L. Vinals, and R. D. Morero, "Fusion of negatively charged phospholipid vesicles by insulin. Relationship with lipid fluidity," Journal of Biological Chemistry, vol. 261, no. 33, pp. 15508-15512, 1986.

[12] T.-Z. Yang, X.-T. Wang, X.-Y. Yan, and Q. Zhang, "Phospholipid deformable vesicles for buccal delivery of insulin," Chemical and Pharmaceutical Bulletin, vol. 50, no. 6, pp. 749753, 2002.

[13] Y.-Y. Huang and C.-H. Wang, "Pulmonary delivery of insulin by liposomal carriers," Journal of Controlled Release, vol. 113, no. 1, pp. 9-14, 2006.

[14] F. Cui, K. Shi, L. Zhang, A. Tao, and Y. Kawashima, "Biodegradable nanoparticles loaded with insulinphospholipid complex for oral delivery: preparation, in vitro characterization and in vivo evaluation," Journal of Controlled Release, vol. 114, no. 2, pp. 242-250, 2006.

[15] B.-Y. Kim, J. H. Jeong, K. Park, and J.-D. Kim, "Bioadhesive interaction and hypoglycemic effect of insulin-loaded lectinmicroparticle conjugates in oral insulin delivery system," Journal of Controlled Release, vol. 102, no. 3, pp. 525-538, 2005.

[16] H. Reithmeier, J. Herrmann, and A. Göpferich, "Lipid microparticles as a parenteral controlled release device for peptides," Journal of Controlled Release, vol. 73, no. 2-3, pp. 339-350, 2001.

[17] N. K. Raman, M. T. Anderson, and C. J. Brinker, "Template-based approaches to the preparation of amorphous, nanoporous silicas," Chemistry of Materials, vol. 8, no. 8, pp. 1682-1701, 1996.

[18] R. K. Rana, Y. Mastai, and A. Gedanken, "Acoustic cavitation leading to the morphosynthesis of mesoporous silica vesicles," Advanced Materials, vol. 14, no. 19, pp. 1414-1418, 2002.

[19] M. R. Knecht and D. W. Wright, "Amine-terminated dendrimers as biomimetic templates for silica nanosphere formation," Langmuir, vol. 20, no. 11, pp. 4728-4732, 2004.

[20] M. Zhao, L. Sun, and R. M. Crooks, "Preparation of $\mathrm{Cu}$ nanoclusters within dendrimer templates," Journal of the American Chemical Society, vol. 120, pp. 4877-4878, 1998.

[21] D. Dollimore and T. Shingles, "Preparation of microporous silica by the technique of freeze-thawing," Journal of Colloid And Interface Science, vol. 29, no. 4, pp. 601-604, 1969.

[22] J. Zhang, Z. Liu, B. Han, et al., "Preparation of silica and $\mathrm{TiO}_{2}$ $\mathrm{SiO}_{2}$ core-shell nanoparticles in water-in-oil microemulsion using compressed $\mathrm{CO}_{2}$ as reactant and antisolvent," Journal of Supercritical Fluids, vol. 36, no. 3, pp. 194-201, 2006.

[23] A. Imhof, "Preparation and characterization of titania-coated polystyrene spheres and hollow titania shells," Langmuir, vol. 17, no. 12, pp. 3579-3585, 2002.

[24] T. Von Werne and T. E. Patten, "Atom transfer radical polymerization from nanoparticles: a tool for the preparation of well-defined hybrid nanostructures and for understanding the chemistry of controlled/"living" radical polymerizations from surfaces," Journal of the American Chemical Society, vol. 123, no. 31, pp. 7497-7505, 2001.

[25] S. Radin, T. Chen, and P. Ducheyne, "The controlled release of drugs from emulsified, sol gel processed silica microspheres," Biomaterials, vol. 30, no. 5, pp. 850-858, 2009.

[26] J. Livage, F. Beteille, C. Roux, M. Chatry, and P. Davidson, "Sol-gel synthesis of oxide materials," Acta Materialia, vol. 46, no. 3, pp. 743-750, 1998.

[27] A. Jintapattanakit, V. B. Junyaprasert, S. Mao, J. Sitterberg, U. Bakowsky, and T. Kissel, "Peroral delivery of insulin using chitosan derivatives: a comparative study of polyelectrolyte nanocomplexes and nanoparticles," International Journal of Pharmaceutics, vol. 342, no. 1-2, pp. 240-249, 2007.

[28] S. Bégu, S. Girod, D. A. Lerner, N. Jardiller, C. Tourné-Péteilh, and J.-M. Devoisselle, "Characterization of a phospholipid bilayer entrapped into non-porous silica nanospheres," Journal of Materials Chemistry, vol. 14, no. 8, pp. 1316-1320, 2004.

[29] H.-P. Hentze, S. R. Raghavan, C. A. McKelvey, and E. W. Kaler, "Silica hollow spheres by templating of catanionic vesicles," Langmuir, vol. 19, no. 4, pp. 1069-1074, 2003.

[30] D. Lootens, C. Vautrin, H. Van Damme, and T. Zemb, "Facetted hollow silica vesicles made by templating catanionic surfactant vesicles," Journal of Materials Chemistry, vol. 13, no. 9, pp. 2072-2074, 2003.

[31] W. Xu, Q. Gao, Y. Xu, D. Wu, and Y. Sun, "pH-Controlled drug release from mesoporous silica tablets coated with hydroxypropyl methylcellulose phthalate," Materials Research Bulletin, vol. 44, no. 3, pp. 606-612, 2009.

[32] W. Xu, Q. Gao, Y. Xu, et al., "Controllable release of ibuprofen from size-adjustable and surface hydrophobic mesoporous silica spheres," Powder Technology, vol. 191, no. 1-2, pp. 13-20, 2009.

[33] C. Charnay, S. Bégu, C. Tourné-Péteilh, L. Nicole, D. A. Lerner, and J. M. Devoisselle, "Inclusion of ibuprofen in mesoporous templated silica: drug loading and release property," European Journal of Pharmaceutics and Biopharmaceutics, vol. 57, no. 3, pp. 533-540, 2004.

[34] Q. Tang, Y. Xu, D. Wu, and Y. Sun, "A study of carboxylicmodified mesoporous silica in controlled delivery for drug famotidine," Journal of Solid State Chemistry, vol. 179, no. 5, pp. 1513-1520, 2006.

[35] C. A. Aerts, E. Verraedt, R. Mellaerts, et al., "Tunability of pore diameter and particle size of amorphous microporous silica for diffusive controlled release of drug compounds," Journal of Physical Chemistry C, vol. 111, no. 36, pp. 13404-13409, 2007.

[36] Y. Li and W. T. Yip, "Liposomes as protective capsules for active silica sol-gel biocomposite synthesis," Journal of the American Chemical Society, vol. 127, no. 37, pp. 12756-12757, 2005.

[37] T. Coradin and J. Livage, "Effect of some amino acids and peptides on silicic acid polymerization," Colloids and Surfaces B, vol. 21, no. 4, pp. 329-336, 2001.

[38] N.-T. Yu, C. S. Liu, and D. C. O'Shea, "Laser Raman spectroscopy and the conformation of insulin and proinsulin," Journal of Molecular Biology, vol. 70, no. 1, pp. 117-132, 1972.

[39] N.-T. Yu, C. S. Liu, J. Culver, and D. C. O'Shea, "A preliminary Raman spectroscopic study of native zinc-insulin crystals," Biochimica et Biophysica Acta, vol. 263, no. 1, pp. 1-6, 1972.

[40] H. Fabian and P. Anzenbacher, "New developments in Raman spectroscopy of biological systems," Vibrational Spectroscopy, vol. 4, no. 2, pp. 125-148, 1993.

[41] H. Böttcher, P. Slowik, and W. Süß, "Sol-gel carrier systems for controlled drug delivery," Journal of Sol-Gel Science and Technology, vol. 13, no. 1-3, pp. 277-281, 1999. 
[42] B. Dahlback, "Blood coagulation," Lancet, vol. 355, no. 9215, pp. 1627-1632, 2000.

[43] B. Sarmento, D. Ferreira, F. Veiga, and A. Ribeiro, "Characterization of insulin-loaded alginate nanoparticles produced by ionotropic pre-gelation through DSC and FTIR studies," Carbohydrate Polymers, vol. 66, no. 1, pp. 1-7, 2006.

[44] B. R. Landau, J. Wahren, V. Chandramouli, W. C. Schumann, K. Ekberg, and S. C. Kalhan, "Contributions of gluconeogenesis to glucose production in the fasted state," Journal of Clinical Investigation, vol. 98, no. 2, pp. 378-385, 1996.

[45] N. Barzilai, D. Massillon, and L. Rossetti, "Effects of fasting on hepatic and peripheral glucose metabolism in conscious rats with near-total fat depletion," Biochemical Journal, vol. 310, no. 3, pp. 819-826, 1995.

[46] P. J. Randle, P. B. Garland, C. N. Hales, and E. A. Newsholme, "The glucose fatty-acid cycle its role in insulin sensitivity and the metabolic disturbances of diabetes mellitus," The Lancet, vol. 281, no. 7285, pp. 785-789, 1963.

[47] L. K. Butler, "Regulation of blood glucose levels in normal and diabetic rats," in Proceedings of the 16th Workshop/Conference of the Association for Biology Laboratory Education (ABLE '95), vol. 16, pp. 181-202, 1995.

[48] P. Kortesuo, M. Ahola, S. Karlsson, I. Kangasniemi, A. YliUrpo, and J. Kiesvaara, "Silica xerogel as an implantable carrier for controlled drug delivery-evaluation of drug distribution and tissue effects after implantation," Biomaterials, vol. 21, no. 2, pp. 193-198, 2000. 

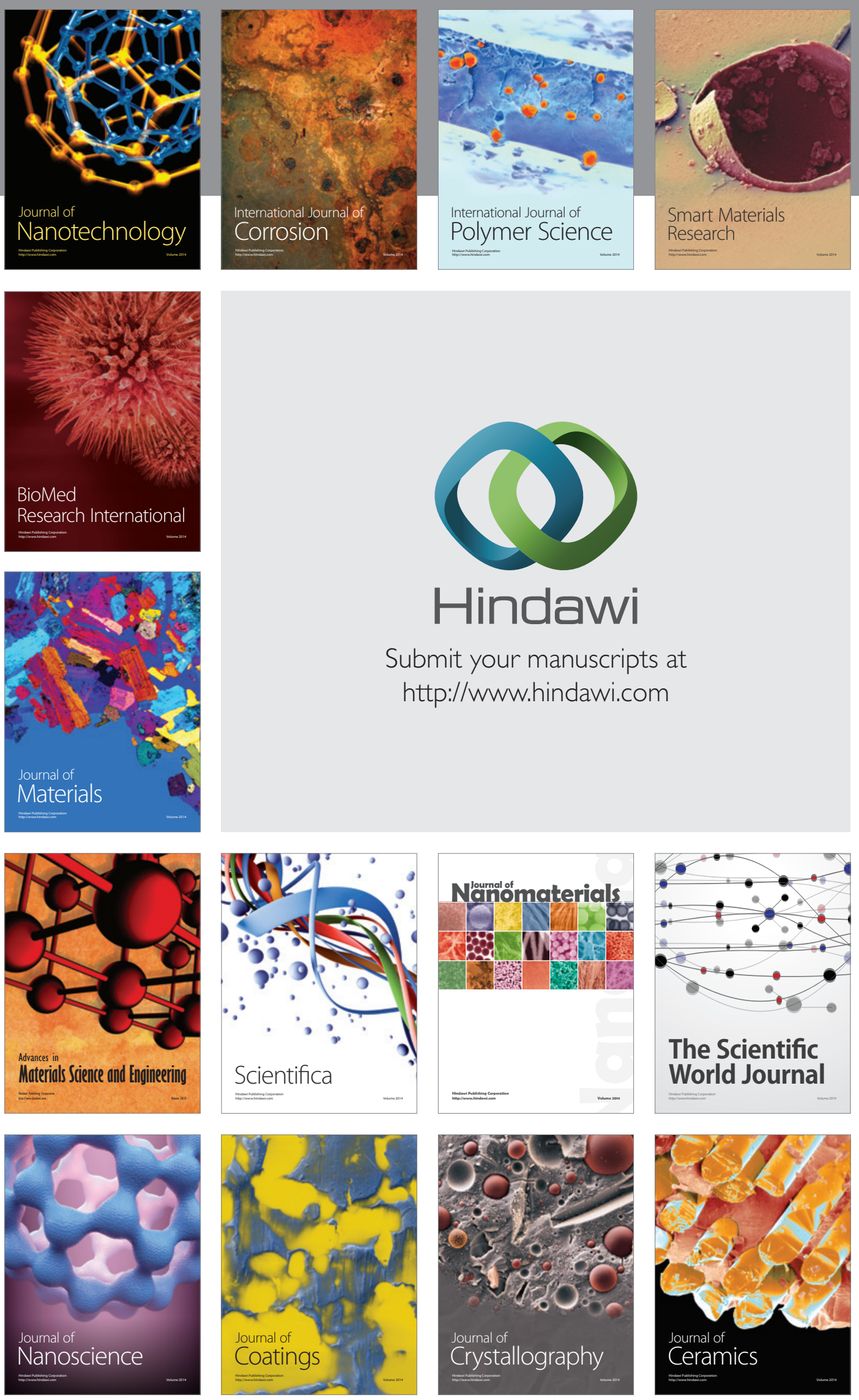

The Scientific World Journal

Submit your manuscripts at

http://www.hindawi.com

\section{World Journal}

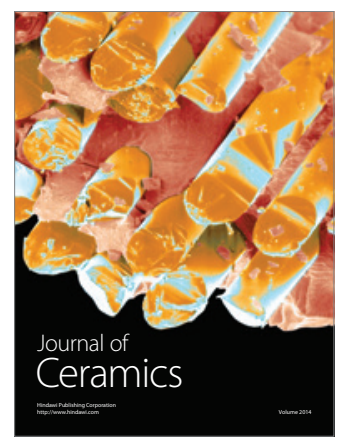

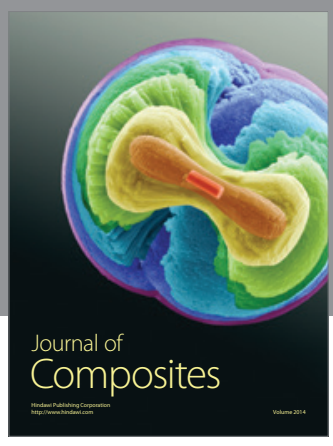
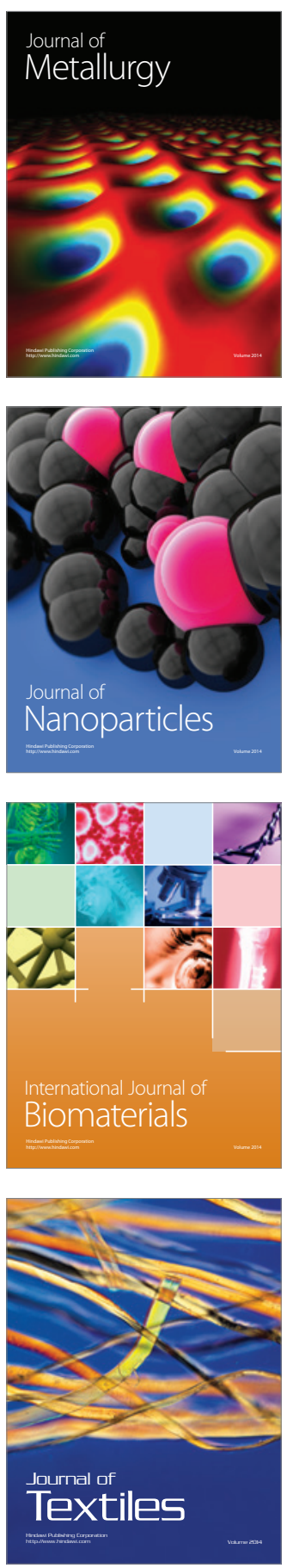